\title{
Electrochemical behavior and conductivity measurements of electropolymerized selenophene-based copolymers
}

\author{
FADI ALAKHRAS* \\ Department of Chemistry, College of Science, University of Dammam 31441 Dammam, Saudia Arabia
}

\begin{abstract}
Electrochemical copolymerization of selenophene and thiophene was performed at a constant electrode potential. The obtained homopolymer films and copolymers were studied and characterized with cyclic voltammetry and conductivity measurements, from which conductivity values around $13.35 \mathrm{~S} \cdot \mathrm{cm}^{-1}$ were determined. The influence of the applied electropolymerization potential and the monomer feed ratio of selenophene and thiophene on the copolymers properties was investigated. The obtained copolymers showed good stability of the redox activity in an acetonitrile-based electrolyte solution. At higher polymerization potentials and at higher concentrations of thiophene in the feed, more thiophene units were incorporated into the copolymer chain. The conductivities of the copolymers were between those of homopolymers, implying that oxidation of both monomers was possible and the copolymer chains might accordingly be composed of both selenophene and thiophene units.
\end{abstract}

Keywords: electropolymerization; intrinsically conducting polymers; polythiophene; polyselenophene

(C) Wroclaw University of Technology.

\section{Introduction}

During the last two decades, intrinsically conducting polymers, such as polypyrrole, polythiophene, polyaniline and poly (para-phenylene) have revealed various areas of potential application, such as materials for battery electrodes [1], gas sensors [2], chemical sensors [3-10], biosensors [1114], ion sieving [15], corrosion protection [16] and microwave shielding [17].

The great significance of these materials is due to the possibility of combining new chemical functions in a backbone. Consequently, both the electrical conductivity and redox stability of the polymers have been improved and exploited in new fields of applications.

Thiophene and its derivatives is one of the most frequent used building blocks in organic semiconducting materials. Polythiophenes are thermally and environmentally stable [18]. They have obtained notable technological potentials in

*E-mail: falakhras@ud.edu.sa electrocatalysis [19, 20], fabrication of molecular electronic devices [21], solid state batteries [22], chemically modified electrodes [23], and biosensors [24-26].

In contrast, its analogue selenophene has not been studied widely due to its higher price, limited number of commercially available derivatives and less developed chemistry. The chemistry of selenophene is quite similar to thiophene chemistry and has been studied in detail in several articles [27-30]. The heteroatom properties can largely affect the properties of conducting polymers.

Computational studies revealed that polyselenophenes should have a lower band gap, a more quinoidal character and a more rigid backbone than polythiophenes. The lower band gap and higher conductivities were ascribed to strong $\mathrm{Se} \cdots \mathrm{Se}$ interactions.

Polyselenophene has been synthesized previously and its chemical, electrochemical and optical properties were investigated [31-38]. However, the quality of the selenophene films was not too good. It was found that the film quality depended 
on the combination of solvent and electrolyte. The conductivity was enhanced to $3.7 \times 10^{-2} \mathrm{~S} \cdot \mathrm{cm}^{-1}$, which was still far below typical values for polythiophenes (10 to $100 \mathrm{~S} \cdot \mathrm{cm}^{-1}$ ). More recently, the electrical conductivity was further increased to $2.8 \times 10^{-1} \mathrm{~S} \cdot \mathrm{cm}^{-1}$ by electropolymerization of selenophene in boron trifluoride diethyl etherate [27].

Further progress in mechanical, physical and chemical properties of polymers can be attained through copolymerization process. During copolymerization, two or more different structures were integrated into a polymer chain. Thus, properties of the resulting materials different from the properties of corresponding homopolymers have been achieved [39]. Concentration of monomer in the feed determines physical and chemical properties of copolymer. Hence, controlling concentration of monomers can lead to copolymers with desired properties [40].

Copolymers of furan and thiophenes were successfully electro-copolymerized. The obtained copolymers were characterized by cyclic voltammetry, infrared spectroscopy, Raman spectroscopy, UV-Vis spectroscopy and electrical conductivity measurements [41-45]. The copolymers showed improved properties in comparison with polyfuran.

The derivatives, like poly(biselenophene) [46], poly[1,2-bis(2-seleninyl)ethane] [47], oligoselenophenes [48] and the copolymers [49] with pyridine [50], were also tested for polymerization and characterization of corresponding polymers with special properties, such as the nonlinear optical ones [51].

In this paper, which is an extension of our work on spectroelectrochemistry of conducting polymers, further attempts to prepare better films of selenophene based copolymers have been carried out.

Results of cyclic voltammetry of homo- and copolymers of selenophene and thiophene are reported. The influence of the applied polymerization potential and the monomer feed ratio on the properties of the copolymers is discussed. In addition, a mechanism of the electrochemical formation of selenophene-thiophene copolymers is proposed. The electrical conductivity and redox stability of the obtained copolymers is investigated and compared with homopolymer films.

\section{Experimental}

Selenophene (TCI, $98 \%$ ) and thiophene (Acros, $99 \%$ ) were distilled under nitrogen just prior to use. Tetrabutylammonium tetrafluoroborate (TBATFB) (Acros, $98 \%$ ) was dried under vacuum at $80^{\circ} \mathrm{C}$ for 24 hours. Acetonitrile (Merck, anhydrous, $<10 \mathrm{ppm} \mathrm{H}_{2} \mathrm{O}$ ) was used without further purification.

The electrochemical polymerizations and examinations were performed in a one-compartment three-electrode cell with the use of a model 150 potentiostat-galvanostat (bio-logic) under computer control (EC-Lab) software. A platinum disc electrode was used as a working electrode and saturated calomel electrode (SCE) as a reference electrode.

The obtained films were grown potentiostatically in acetonitrile solution containing in addition $0.1 \mathrm{M}$ TBATFB as a supporting electrolyte, at room temperature and at a constant electrode potential for 2 minutes. The constant electrode potential for the preparation of copolymer films was chosen according to the threshold polymerization potential of the homopolymers. After polymerization the film was washed with acetonitrile to remove any traces of mono- and oligomers.

Cyclic voltammetry of the polymers was carried out in a monomer free acetonitrile solution containing $0.1 \mathrm{M}$ TBATFB as a supporting electrolyte.

Conductivity measurements at room temperature were performed using four-probe technique (SES Instruments Pvt. Ltd.). The homo- and copolymer films were deposited onto a platinum sheet electrode (approximate surface area $1.5 \mathrm{~cm}^{2}$ ). After doping to desired potentials, the deposited films were scraped off from the electrode surface, dried and then pressed into discs with relatively thin thickness $(\sim 200 \mathrm{~nm})$.

Before each polymerization, the platinum disc electrode was carefully polished with a diamond polishing paste down to $0.1 \mu \mathrm{m}$ and then to $0.05 \mu \mathrm{m}$ with aqueous alumina slurry, and cleaned with water and acetone successively, then dried by 
a blower. All solutions were deaerated by a dry $\mathrm{N}_{2}$ stream for $10 \mathrm{~min}$ before the experiment and a slight $\mathrm{N}_{2}$ over-pressure was maintained during the experiment.

\section{Results and discussion}

\subsection{Electropolymerization of homo- and copolymer films}

The two freshly distilled selenophene and thiophene were tested to be very stable during the whole experiment and could be directly used for the electrochemical polymerization of homo- and copolymer films.

Fig. 1 shows the anodic polarization curves of monomers in acetonitrile solution containing in addition 0.1 M TBATFB. The background electrolyte is electrochemically silent in the whole potential range. It can be clearly seen that the oxidation onset of selenophene (threshold polymerization potential) is initiated at $\mathrm{E}_{\mathrm{SCE}}=1.55 \mathrm{~V}$ (curve b), which is lower than that of thiophene $\mathrm{E}_{\mathrm{SCE}}=1.7 \mathrm{~V}$ (curve a).

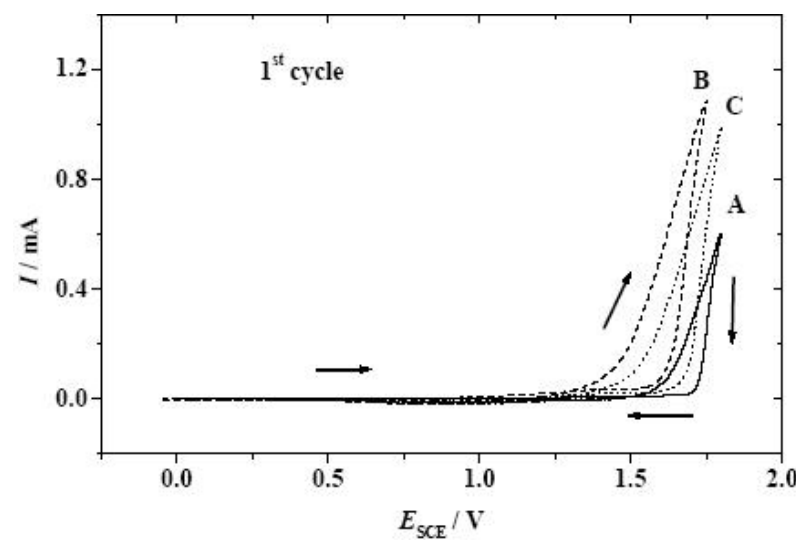

Fig. 1. CVs of (A) $0.1 \mathrm{M}$ thiophene, (B) $0.1 \mathrm{M}$ selenophene, (C) $0.1 \mathrm{M}$ selenophene and $0.1 \mathrm{M}$ thiophene in a solution of acetonitrile $+0.10 \mathrm{M}$ TBATFB. $\mathrm{dE} / \mathrm{dt}=100 \mathrm{mV} / \mathrm{s}$.

The lower is the monomer oxidation onset the less is the possibility of kink coupling, such as $\alpha-\beta$ coupling and overoxidation. Thus, the quality of asformed conducting polymers would be improved. This result implies that the replacement of sulfur by selenium would have a positive effect on the final conducting polymers [27].

The small difference between the oxidation potentials of the two monomers suggests a large probability of copolymerization of the two monomers. Curve $\mathrm{C}$ was obtained when a current-potential curve was recorded in a solution containing $0.10 \mathrm{M}$ selenophene and $0.10 \mathrm{M}$ thiophene. However, the superposition of curve A and curve B does not simply add up to curve C. This might be caused by changes in the electrochemical environment, such as electrode roughness $[52,53]$. The oxidation potential of the mixture of selenophene and thiophene is around $\mathrm{E}_{\mathrm{SCE}}=1.60$ to $1.65 \mathrm{~V}$, which is between the oxidation potentials of the two monomers, implying that oxidation of both monomers is likely, thus, the copolymer chains may accordingly be composed of selenophene and thiophene units $[41,44,52]$.

\subsection{Electrochemistry of homo- and copolymer films}

The electrochemical behaviors of the homopolymer films deposited electrochemically were studied in acetonitrile-based electrolyte solution (Fig. 2A, C). Similar to the results presented in the literature [27, 41], the steady-state CVs represent broad anodic and cathodic peaks. For polyselenophene (A), there is a broad anodic peak at $\mathrm{E}_{\mathrm{SCE}}=1.04 \mathrm{~V}$ caused by polymer oxidation and a corresponding broad cathodic peak around $\mathrm{E}_{\mathrm{SCE}}=0.76 \mathrm{~V}$ due to polymer reduction. Polythiophene $(\mathrm{C})$ can be oxidized and reduced from 1.38 to $0.66 \mathrm{~V}$. The broad redox waves in their $\mathrm{CVs}$ are commonly observed in the electrochemistry of intrinsically conducting polymers and can be ascribed to the diffusion of the dopant ions in and out of the film as well as to the presence of coupling defects distributed statically, which results in a series of energetically nonequivalent chain segments [41, 44, 54, 55].

Copolymerization was carried out under potentiostatic conditions. Fig. 2B shows a typical cyclic voltammogram of a copolymer obtained from a solution containing $0.10 \mathrm{M}$ selenophene and $0.10 \mathrm{M}$ thiophene, prepared at $\mathrm{E}_{\mathrm{SCE}}=1.65 \mathrm{~V}$. Only one 


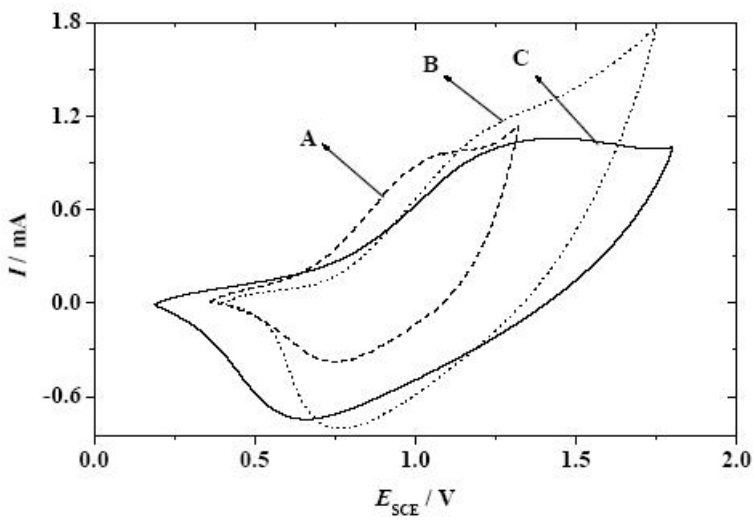

Fig. 2. CVs recorded in a monomer free acetonitrile solution $+0.10 \mathrm{M}$ TBATFB (A) polyselenophene deposited at $\mathrm{E}_{\mathrm{SCE}}=1.55 \mathrm{~V}$ in a solution containing 0.1 M selenophene, (B) copolymer deposited at $\mathrm{E}_{\mathrm{SCE}}=1.65 \mathrm{~V}$ in a solution containing $0.1 \mathrm{M}$ selenophene and $0.1 \mathrm{M}$ thiophene, (C) polythiophene deposited at $\mathrm{E}_{\mathrm{SCE}}=1.70 \mathrm{~V}$ in a solution containing $0.1 \mathrm{M}$ thiophene. $\mathrm{dE} / \mathrm{dt}$ $=100 \mathrm{mV} / \mathrm{s}$.

anodic/cathodic peak couple appears for the copolymer film at a position quite different from the positions observed for homopolymers. The appearance of one redox peak indicates uniform redox properties. Determination of the deposition charge of the copolymer films is possible but the result is of only limited value because the fraction of charge consumed in polymer formation vs. the formation of oligomers or the fraction consumed in other reactions is not known. The charge transferred in the CVs of the films may indeed be determined; this may provide some information about the amount of electrochemically active polymer. This does not provide any information about film thickness or film conductivity: these properties may influence most likely the film response. Determination of film thickness has been a permanent subject of discussion; in case of polypyrrole and polyaniline some approximations have been reported, whereas nothing even distantly similar has been reported on polyselenophene or the copolymers studied here. Nevertheless, more attention toward the Faradaic redox charge as a function of deposition parameters will be devoted in ongoing and future work. Furthermore, both cathodic and anodic currents of the obtained copolymer are higher than those found for the homopolymers, especially for polyselenophene. This implies that the electrochemical activity (redox capacity) of the copolymer is higher after the same time of electropolymerization. The copolymer is more stable and less affected by overoxidation, presumably due to the existence of thiophene units in the copolymer chains, which may increase the stability of the film.

The CVs also show a pronounced hysteresis, i.e. a considerable difference between the anodic and cathodic peak potentials, up to $0.45 \mathrm{~V}$, as shown in Fig. 2B. The main reasons accounting for this phenomenon are usually as follows: slow heterogeneous electron transfer, effects of local rearrangements of polymer chains, slow mutual transformations of various electronic species [27, 55].

Electrochemical copolymerization both at different potentials and for different thiophene concentrations was investigated. Fig. 3 shows CVs of the copolymers obtained by electropolymerization in solutions containing $0.1 \mathrm{M}$ selenophene and $0.1 \mathrm{M}$ thiophene at potentials ranging from $\mathrm{E}_{\mathrm{SCE}}=1.6$ to $1.7 \mathrm{~V}$. The anodic peak potential of the copolymers shifts to higher values with increasing polymerization potential of the copolymer films. When prepared at $\mathrm{E}_{\mathrm{SCE}}=1.6 \mathrm{~V}$, the copolymer shows an anodic peak at $\mathrm{E}_{\mathrm{SCE}}=1.14 \mathrm{~V}$ and cathodic peak at $\mathrm{E}_{\mathrm{SCE}}=0.85 \mathrm{~V}$, whereas the copolymer prepared at $\mathrm{E}_{\mathrm{SCE}}=1.7 \mathrm{~V}$ shows redox peaks at $\mathrm{E}_{\mathrm{SCE}}=1.30 \mathrm{~V}$ and at $\mathrm{E}_{\mathrm{SCE}}=0.72 \mathrm{~V}$, respectively. The former peak pair is closer to polyselenophene, whereas the latter one is closer to polythiophene. This indicates that more thiophene units are incorporated into the copolymer chain with increasing preparation potential.

The electrochemical characteristics of both the homopolymers and copolymers displayed in Fig. 2 and Fig. 3 indicate that keeping the potential of electrosynthesis of copolymers formed in mixed solutions near the threshold potential for electropolymerization of selenophene may result in the selenophene-based copolymers and vice versa.

When the selenophene/thiophene feed ratio is changed from $1: 1$ to $3: 1(0.1 \mathrm{M} / 0.033 \mathrm{M}), \mathrm{CVs}$ as shown in Fig. 4A are obtained; at a ratio of 6:1 (0.1 M / 0.0166 M), CVs shown in Fig. 4B 


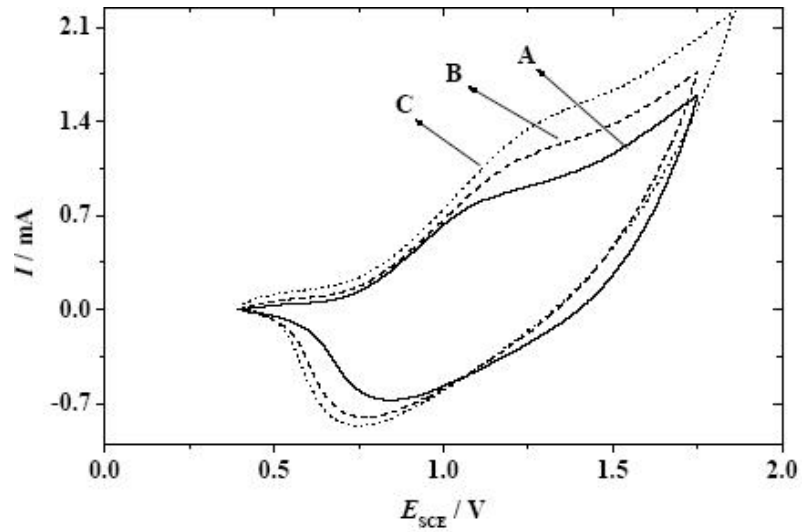

Fig. 3. CVs recorded in a monomer free acetonitrile solution $+0.10 \mathrm{M}$ TBATFB of copolymers deposited at $\mathrm{E}_{\mathrm{SCE}}=$ (A) $1.60 \mathrm{~V}$, (B) $1.65 \mathrm{~V}$, (C) $1.7 \mathrm{~V}$ in a solution containing selenophene: thiophene (mole ratio $1: 1) . \mathrm{dE} / \mathrm{dt}=100 \mathrm{mV} / \mathrm{s}$.

result. Only one redox peak couple appears, which can be attributed to the p-doping/undoping processes of the films. Up shift of the anodic peak with increasing preparation potentials is also observed. When comparing CVs of the copolymers prepared at the same polymerization potential with different monomer feed ratios, the lower concentration of thiophene leads to a negative shift of the anodic peak potentials of the copolymer. This implies that more thiophene units are incorporated into the copolymer film when the concentration of thiophene increases (Fig. 5).

The peak potential values of the copolymers prepared at different potentials from these three different solutions are listed in Table 1; the peak potentials of homopolymers are added for comparison. All the above results indicate that the electrochemical properties of the copolymers depend not only on the electrochemical polymerization potential but also on the monomer feed ratio. Apparently, the dependence of the electrochemical properties of the copolymer on the electropolymerization potential and monomer feed ratio reflects the composition and perhaps even the structure of the copolymers [41-45].

Fig. 6 shows $\mathrm{CVs}$, at $\mathrm{dE} / \mathrm{dt}=25,50,75$ and $100 \mathrm{mV} / \mathrm{s}$, of copolymer films deposited at $\mathrm{E}_{\mathrm{SCE}}=1.65 \mathrm{~V}$ in a solution containing $1: 1$
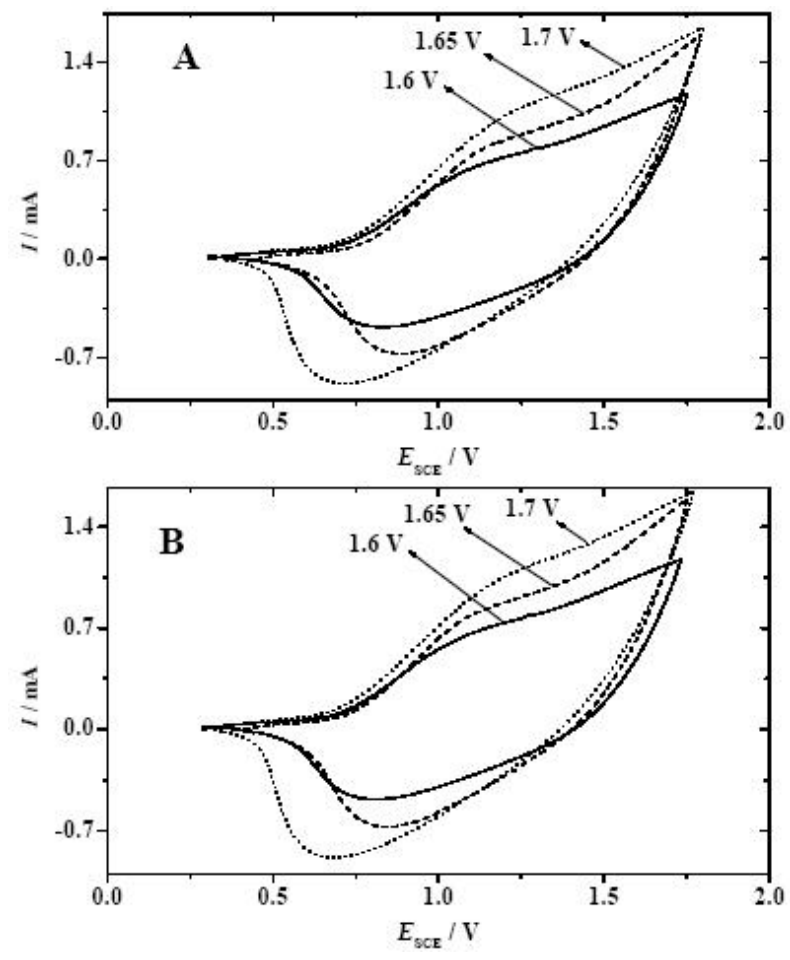

Fig. 4. CVs recorded in a monomer free acetonitrile solution $+0.10 \mathrm{M}$ TBATFB of copolymers deposited at $\mathrm{E}_{\mathrm{SCE}}$ ranging from 1.6 to $1.7 \mathrm{~V}$, respectively, in a solution containing selenophene: thiophene mole ratio (A) 3:1, (B) 6:1. dE/dt $=$ $100 \mathrm{mV} / \mathrm{s}$.

monomer ratio. The redox currents are proportional to the square root of the scanning rates, indicating a redox coupling fixing on the electrode and diffusion-controlled character of the electrochemical processes [56, 57]. For a diffusioncontrolled process the straight line should pass through the origin, but in the case of conducting polymers, deviations from the ideal behavior may arise from contributions, such as double-layer charging, which can disturb the zero intercept [58].

\subsection{Stability of redox activity of homo- and copolymer films}

Selenophene-thiophene copolymers confirm reasonably a good long-term stability of redox activity after cycling in acetonitrile comparing with polyselenophene film. As shown in Fig. 7, the peak separation of anodic and cathodic peaks is between 
Table 1. Peak potentials of the copolymers prepared at various electropolymerization potentials $\mathrm{E}_{\mathrm{pol}}$ from acetonitrile solutions containing different monomer feed ratios. (Peak potentials of homopolymers are added for comparison).

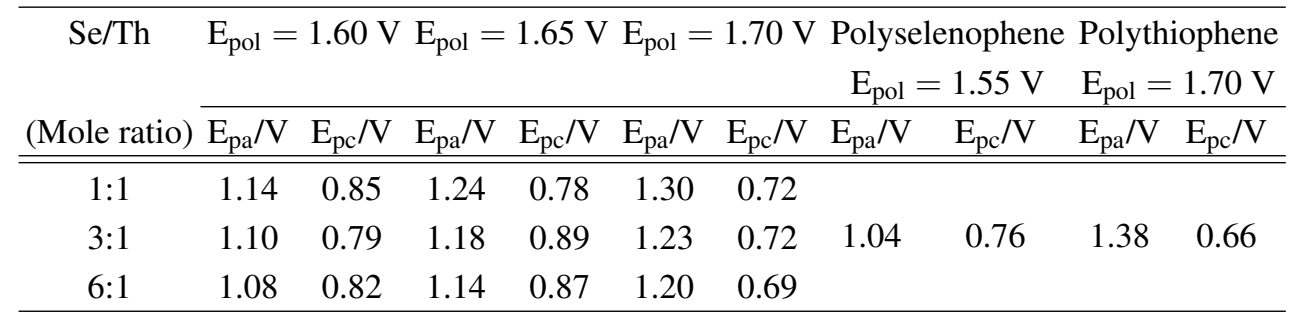
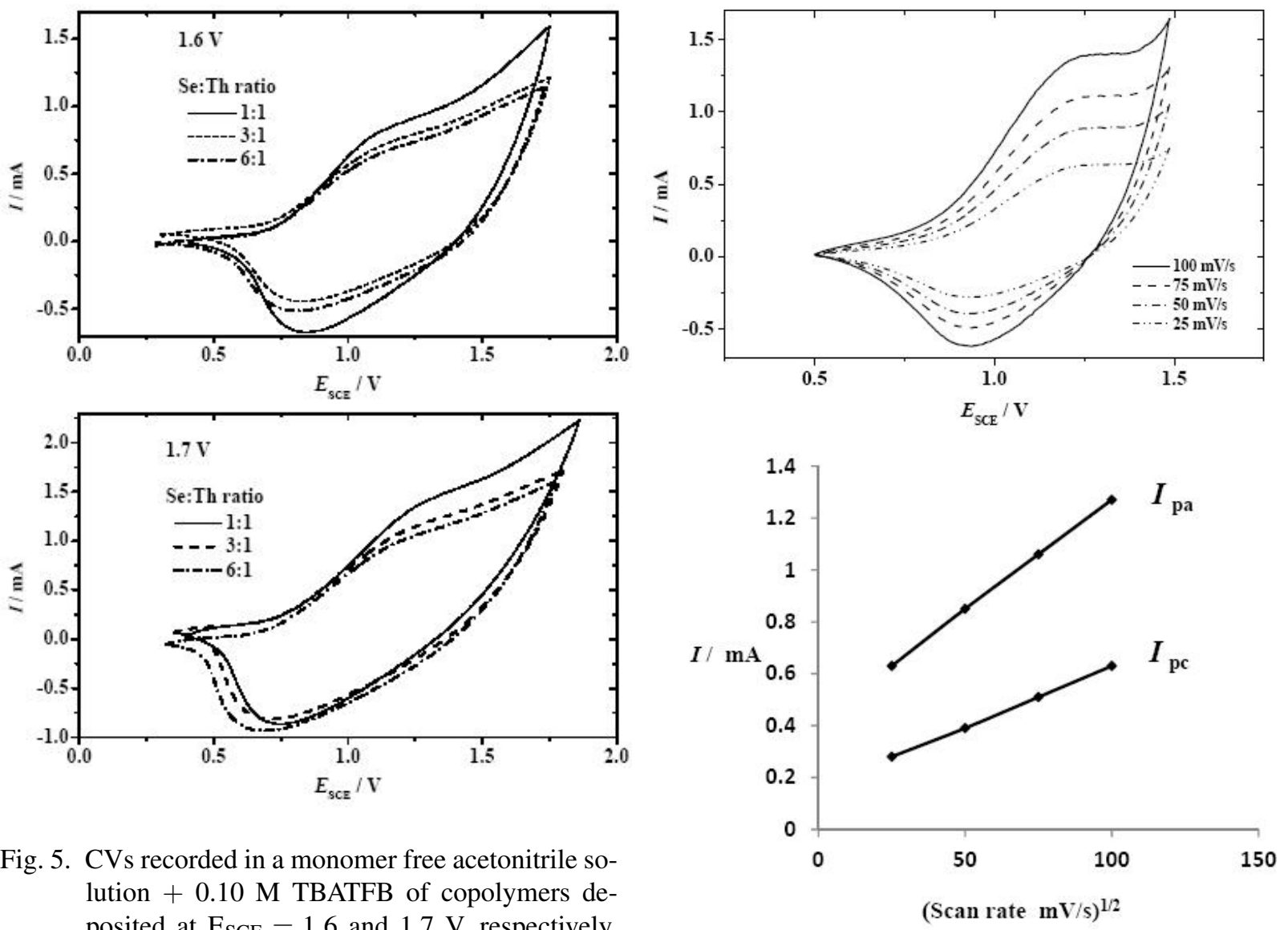

Fig. 5. CVs recorded in a monomer free acetonitrile solution $+0.10 \mathrm{M}$ TBATFB of copolymers deposited at $\mathrm{E}_{\mathrm{SCE}}=1.6$ and $1.7 \mathrm{~V}$, respectively, in a solution containing selenophene: thiophene (mole ratio $1: 1,3: 1,6: 1) ; \mathrm{dE} / \mathrm{dt}=100 \mathrm{mV} / \mathrm{s}$.

0.28 to $0.58 \mathrm{~V}$, which may lead to the conclusion that the process is close to being reversible (i.e. fast) but still some irreversible processes occur during cycling. This behavior is a general tendency and is commonly observed in the electrochemistry of intrinsically conducting polymers [44, 54, 55].

Fig. 6. CVs recorded in a monomer free acetonitrile solution $+0.10 \mathrm{M}$ TBATFB of copolymer films deposited at $\mathrm{E}_{\mathrm{SCE}}=1.65 \mathrm{~V}$ in a solution containing $0.1 \mathrm{M}$ selenophene and $0.1 \mathrm{M}$ thiophene; $\mathrm{dE} / \mathrm{dt}=25,50,75$, and $100 \mathrm{mV} / \mathrm{s}$.

The obtained films can be cycled repeatedly between the conducting (oxidized) and insulating (neutral) states with slight decrease in electroactivity of the materials. The retention of the redox 

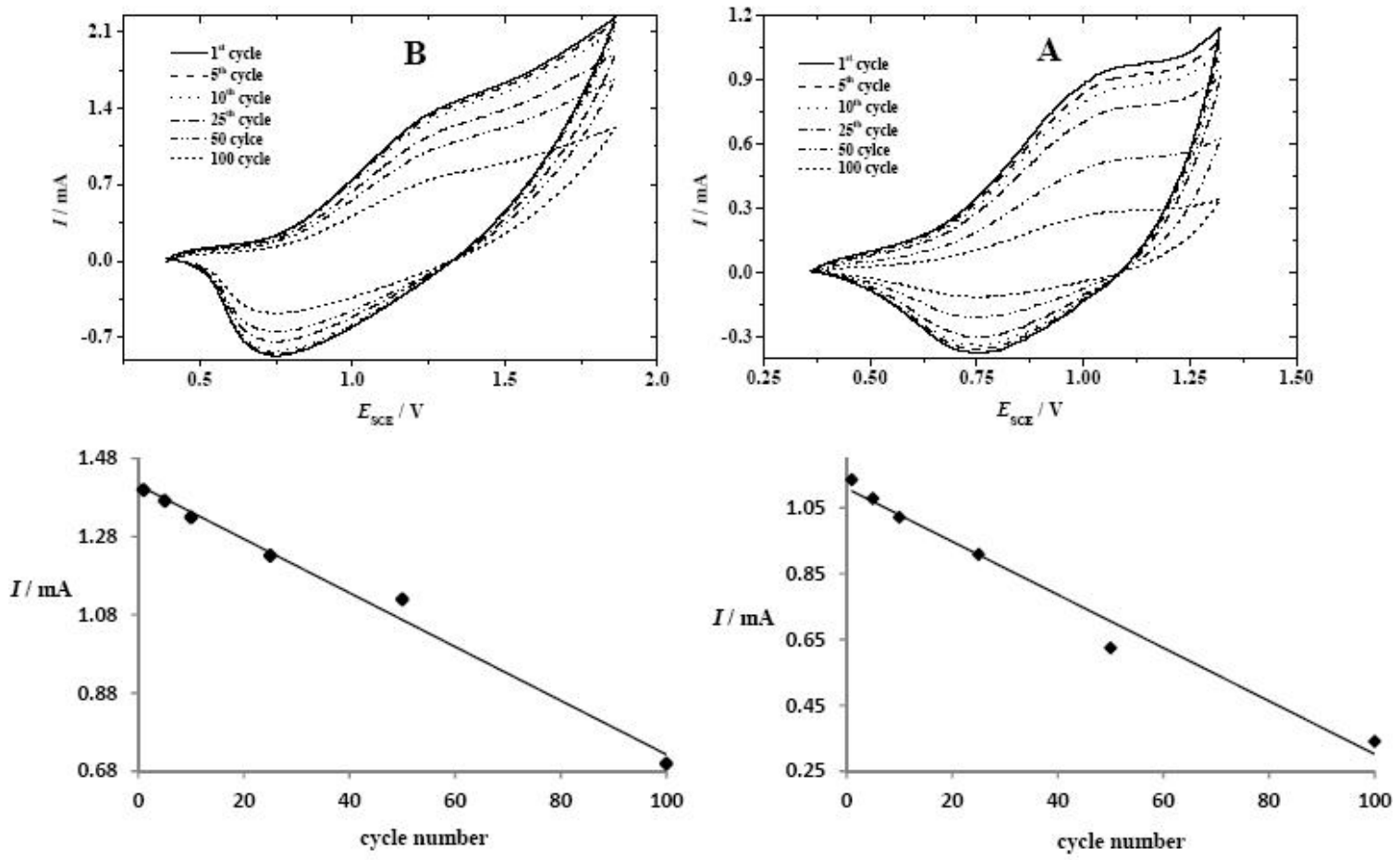

Fig. 7. $1^{\text {st }}, 5^{\text {th }}, 25^{\text {th }}, 50^{\text {th }}$, and $100^{\text {th }} \mathrm{CVs}$ recorded in a monomer free acetonitrile solution $+0.10 \mathrm{M}$ TBATFB of polyselenophene (A) and copolymer (B) deposited at $\mathrm{E}_{\mathrm{SCE}}=1.70 \mathrm{~V}$ in a solution containing Se: Th, mole ratio $1: 1 ; \mathrm{dE} / \mathrm{dt}=100 \mathrm{mV} / \mathrm{s}$.

activity of a copolymer film after 100 times cycling in dry acetonitrile is about $50 \%$, whereas for selenophene homopolymer it is only $30 \%$ (in terms of peak current), indicating the coexistence of both long and short conjugation lengths in the polymer chains. As shown in the insets, the anodic peak current decreases as the number of potential cycles increases, indicating a decrease in the redox activity. Additionally the stability of the copolymer film declines sharply after exceeding 50 cycles, while polyselenophene stability decreases noticeably beyond 25 cycles (Fig. 8).

However, when the copolymer film is cycled in an aqueous solution, the redox activity is totally lost and a very large anodic peak current around $1.53 \mathrm{~V}$ appears, without the associated cathodic one (Fig. 9). This process is independent of $\mathrm{pH}$ value of the aqueous solution indicating that water molecules are involved in this degradation process instead of protons or hydroxyl ions [41, 59]. Moreover, the redox activity of the copolymer film is strongly affected when the $\mathrm{CV}$ is recorded

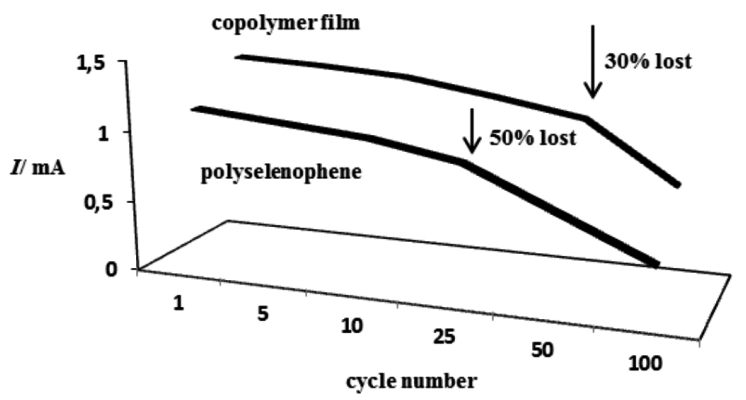

Fig. 8. Dependence of redox activity of polyselenophene and copolymer deposited at $\mathrm{E}_{\mathrm{SCE}}=1.70 \mathrm{~V}$ in a solution containing Se:Th, mole ratio $1: 1$ on cycle numbers.

in wet acetonitrile $\left(\mathrm{H}_{2} \mathrm{O}: 1 \%\right.$ by volume). The associated loss of redox capacity during the oxidation process may be caused by the destruction of conjugated structures. For more details, an electrochemical degradation mechanism for selenophenethiophene copolymers in acetonitrile and in aqueous solution will be proposed based on FT-IR spectroscopy data and published subsequently. 


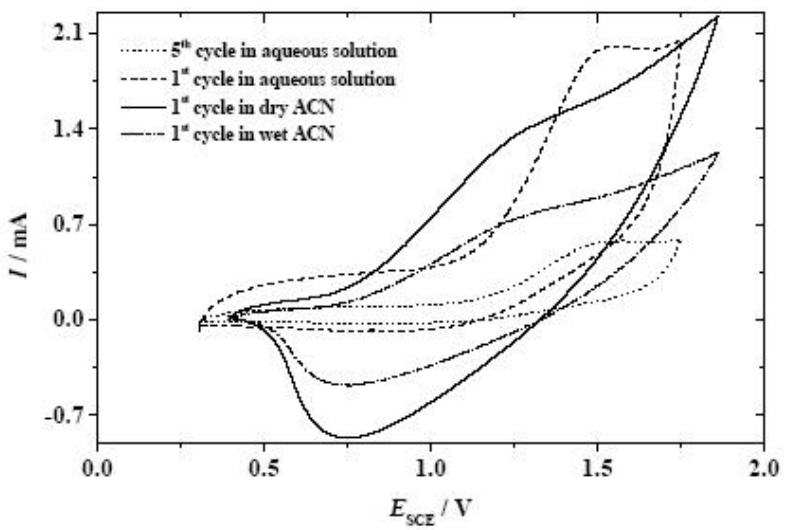

Fig. 9. CVs recorded in an aqueous solution containing $0.10 \mathrm{M}$ NaTFB and in an acetonitrile/ $\mathrm{H}_{2} \mathrm{O}$ (volume ratio 100:1)+ $0.10 \mathrm{M}$ TBATFB solution of copolymer deposited at $\mathrm{E}_{\mathrm{SCE}}=1.70 \mathrm{~V}$ in a solution containing selenophene: thiophene, mole ratio $1: 1, \mathrm{dE} / \mathrm{dt}=100 \mathrm{mV} / \mathrm{s}$.

\subsection{Conductivity measurements of homo- and copolymer films}

Polyselenophene shows a single conductivity change starting at $\mathrm{E}_{\mathrm{SCE}}=0.0 \mathrm{~V}$ with a stable conductivity up to $\mathrm{E}_{\mathrm{SCE}}=1.4 \mathrm{~V}$ (Fig. 10A). Upon oxidation, the conductivity sharply increases above $\mathrm{E}_{\mathrm{SCE}}=0.9 \mathrm{~V}$ and reaches around $0.45 \mathrm{~S} \cdot \mathrm{cm}^{-1}$. When the applied potential is increased, the conductivity of polythiophene film is further enhanced above $\mathrm{E}_{\mathrm{SCE}}=1.2 \mathrm{~V}$ and attains around $33 \mathrm{~S} \cdot \mathrm{cm}^{-1}$ (Fig. 10B)

The lower electrical conductivity of polyselenophene compared with polythiophene can be ascribed to the overoxidation which cannot be totally suppressed during the polymerization process even in small amount. Moreover, the increase in size of the heteroatom leads to larger interchain distances in the solid and prevents hopping among chains [32].

Conductivity measurements both at different polymerization potentials and with different monomer feed ratios have been performed. The copolymer films still show a single change in conductivity during the oxidation (Fig. 11). When the polymerization potential changes from $\mathrm{E}_{\mathrm{SCE}}=$ $1.6 \mathrm{~V}$ to $\mathrm{E}_{\mathrm{SCE}}=1.7 \mathrm{~V}$ the conductivity increases from around $8.34 \mathrm{~S} \cdot \mathrm{cm}^{-1}$ to $13.35 \mathrm{~S} \cdot \mathrm{cm}^{-1}$,
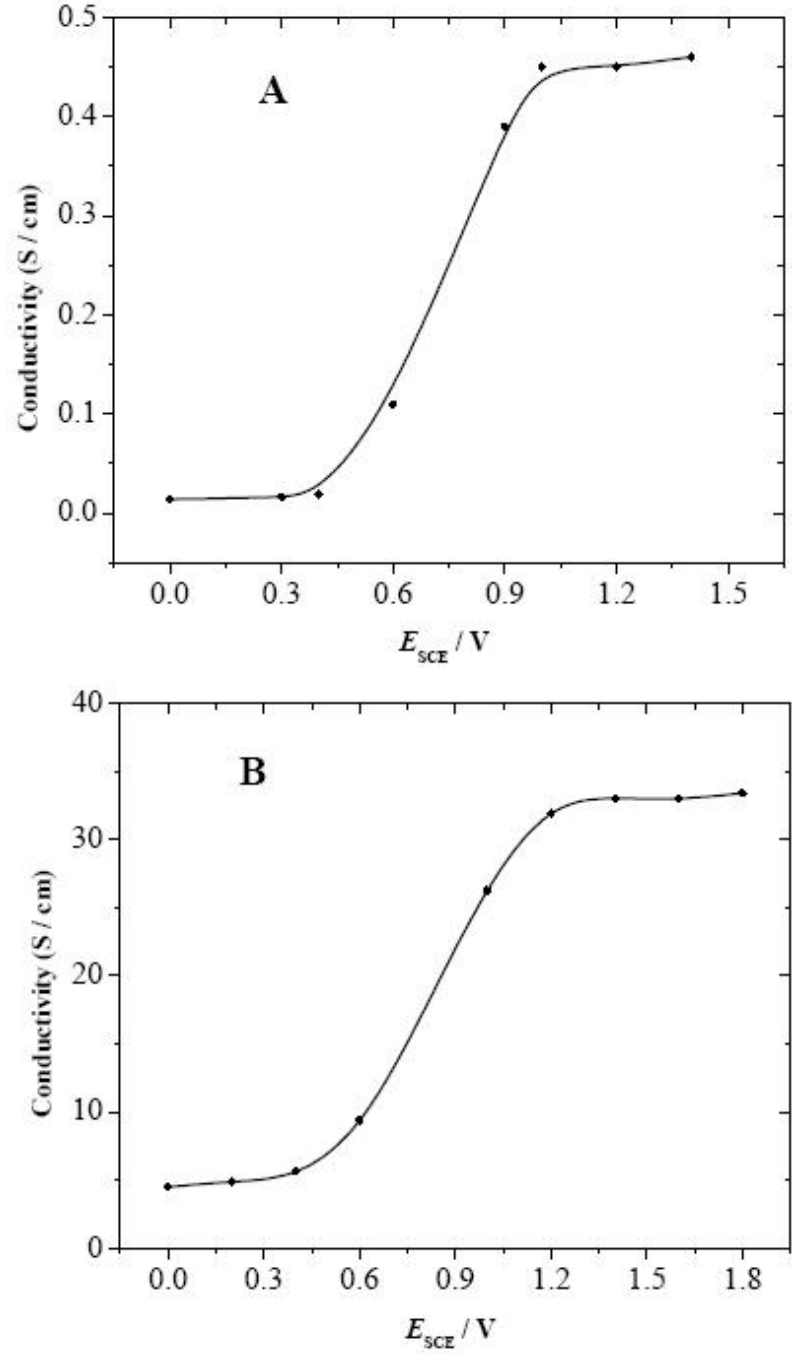

Fig. 10. Conductivity versus electrode potential data of (A) polyselenophene deposited at $\mathrm{E}_{\mathrm{SCE}}=1.55$ and (B) polythiophene deposited at $\mathrm{E}_{\mathrm{SCE}}=$ $1.70 \mathrm{~V}$.

respectively. When selenophene/thiophene feed ratio is changed from $6: 1$ to $1: 1$, the conductivity is clearly improved and increases from $2.30 \mathrm{~S} \cdot \mathrm{cm}^{-1}$ to $8.34 \mathrm{~S} \cdot \mathrm{cm}^{-1}$, respectively.

Based on the above results, we may conclude that the number of thiophene units in these copolymer chains increases with increasing the polymerization potential and with an increase of thiophene concentration in the polymerization solutions. In addition, the conductivities of the copolymers are between those of homopolymers, implying that oxidation of both monomers is possible and the 


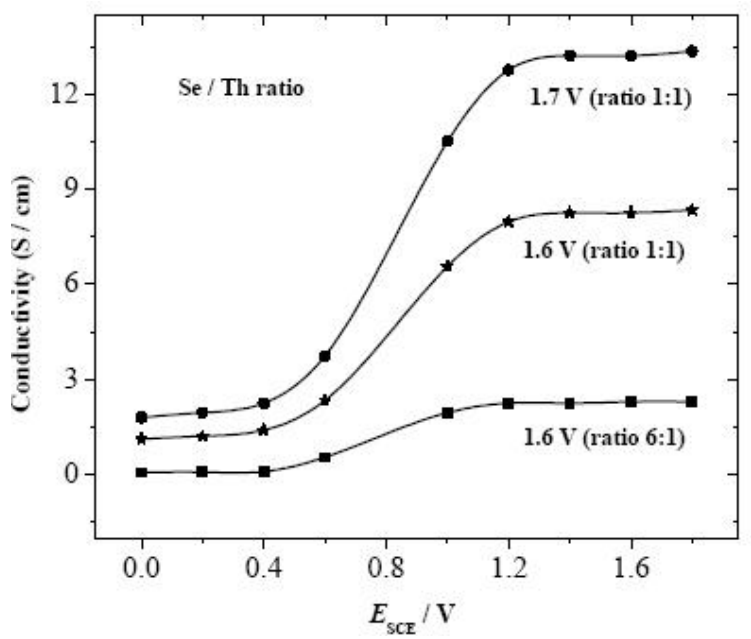

Fig. 11. Conductivity versus electrode potential data of copolymers deposited at $\mathrm{E}_{\mathrm{SCE}}=1.60$ and $1.70 \mathrm{~V} \mathrm{Se} / \mathrm{Th}$ (1:1), and copolymer deposited at $\mathrm{E}_{\mathrm{SCE}}=1.6 \mathrm{Se} / \mathrm{Th}(6: 1)$.

copolymer chains may accordingly be composed of both selenophene and thiophene units [44]. It can be concluded that the copolymerization technique is fruitful for effective modification of the conductivity of polyselenophene, which can make it more useful for different potential applications.

More importantly, the conductivity properties are not the sum of those of the two individual homopolymers. This outcome may exclude the probability of having block copolymers [42]. The film deposited at $\mathrm{E}_{\mathrm{SCE}}=1.7 \mathrm{~V}$ with 1:1 feed ratio may have a structure close to those of polythiophenebased random copolymers, while the film obtained at $\mathrm{E}_{\mathrm{SCE}}=1.6 \mathrm{~V}$ with $6: 1$ feed ratio may be considered as polyselenophene-based random copolymer.

The electrochemistry of the deposited polymer films is further supported with the observations and suggestions obtained from the results of conductivity measurements (more detailed discussion will be published soon).

\subsection{Proposed mechanism of electrochem- ical formation of copolymer films}

The electropolymerization mechanism of copolymers is presumably even more complex than that of homopolymers [60]. Fig. 12 shows

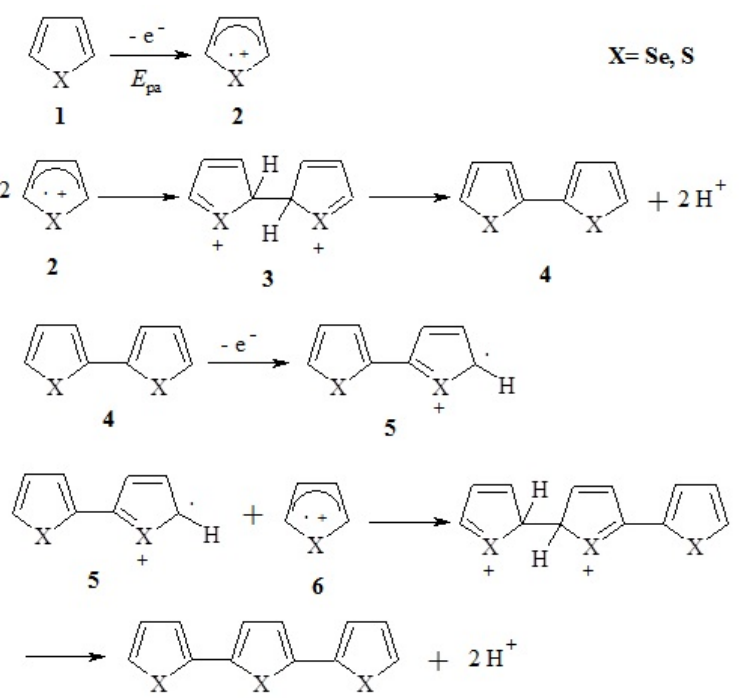

Fig. 12. Proposed mechanism of the electropolymerization of selenophene-thiophene copolymers.

a proposed mechanism of the electropolymerization of selenophene and thiophene based on already known coupling reactions of aromatic compounds [61-63]. The first electrochemical step (E) is the oxidation of the monomer (1) into its radical cation. The second step involves the coupling of two radicals (2) to produce a dihydrodimer (3) dication that leads to a dimer (4) after the loss of two protons and rearomatization. This rearomatization constitutes the driving force of the chemical step (C). At the applied electrode potential, the dimer (4), which is more easily oxidized than the monomer, is present in its radical form (5) and undergoes further coupling with a monomeric radical (6). Electropolymerization then proceeds through successive electrochemical and chemical steps according to a general $\mathrm{E}(\mathrm{EC}) \mathrm{n}$ mechanism until the oligomer becomes insoluble in the electrolyte solution and precipitates onto the electrode surface; soluble oligomers were observed to stray away from the electrode at the beginning of the polymerization.

\section{Conclusions}

Electrochemical copolymerization of selenophene and thiophene was successfully carried out in acetonitrile solution containing in addition 
$0.1 \mathrm{M}$ TBATFB as a supporting electrolyte at constant electrode potential. CVs of the copolymer films show intermediate electrochemical properties between homopolymers. The homoand copolymer films have only one redox peak caused by polymer oxidation and reduction. At higher polymerization potentials and at higher concentrations of thiophene in the feed, more thiophene units are incorporated into the copolymer chain. The copolymer materials show fairly good stability of the redox activity in organic solvents. The conductivities of the copolymers are between those of homopolymers, implying that oxidation of both monomers is possible and the copolymer chains may accordingly be composed of both selenophene and thiophene units. A mechanism of the electropolymerization of selenophene and thiophene based on already known coupling reactions of aromatic compounds has been proposed.

\section{Acknowledgements}

Financial support from the Deanship of Scientific Research at the University of Dammam (Project No. 2012046) is gratefully acknowledged.

\section{References}

[1] Amanokura J., SUZUKi Y., IMABAYASHI S., Watanabe M., J. Electrochem. Soc., 148 (2001), D43.

[2] Sotzing G.A., Briglin S.M., Grubbs R.H., LEWIS N.S., Anal. Chem., 72 (2000), 3181.

[3] Lin C.W., Hwang B.J., LeE C.R., J. Appl. Polym. Sci., 73 (1999), 2079.

[4] Malinauskas A., Malinauskiene J., RamanaviCIUS A., Nanotechnology, 16 (2005) R51.

[5] James D., Scott S.M., Ali Z., Ohare W.T., Microchim. Acta, 149 (2005), 1.

[6] Guernion N.J.L., Hayes W., Curr. Org. Chem., 8 (2004), 637.

[7] Vidal J.C., Garciaruiz E., Castillo J.R., Microchim. Acta, 143 (2003), 93.

[8] Dai L.M., Soundarrajan P., Kim T., Pure Appl. Chem., 74 (2002), 1753.

[9] Trojanowicz M., Velkrawczyk T.K., AlexanDER P.W., Anal. Chem., 42 (1997), 199.

[10] Trojanowicz M., Microchim. Acta, 143 (2003), 75.

[11] Cosnier S., Anal. Bioanal. Chem., 377 (2003), 507.

[12] Bartlett P.N., Birkin P.R., Synthetic Met., 61 (1993), 15.

[13] SADIK O.A., Electroanal., 11 (1999), 839.

[14] Wallace G.G., SMYth M., ZhaO H., TRAC-Trend. Anal. Chem., 18 (1999), 245.
[15] Shinohara H., Aizawa M., Shirakawa H., J. Chem. Soc. Chem. Commun., 24 (1986), 87.

[16] Le H.N.T., Garcia B., Deslouis C., Xuan Q.L., J. Appl. Electrochem., 32 (2002), 105.

[17] BuCKLey L.J., EAshoo M., Synthetic Met., 78 (1996), 1.

[18] Kelkar D., Chourasia A., Chem. Chem. Tech., 5 (2011), 309.

[19] Malinauskas A., Synthetic Met., 107 (1999), 75.

[20] Grundmeier G., Schmidt W., Stretmann M., Electrochim. Acta, 45 (2000), 2515.

[21] Gurunathan K., Mrurgan A.V., Marimuthu R., Mulik U.P., Amalnerkar D.P., Mater. Chem. Phys., 61 (1999), 173.

[22] Otero T.F., Cantero I., J. Power Sources, 81 (1999), 838.

[23] Fritz B., PAUl R., Electrochim. Acta, 45 (2000), 2467.

[24] Wallace G.G., TRAC-Trend. Anal. Chem., 18 (1999), 443.

[25] Cosnier S., Biosen. Bioelectron., 14 (1999), 443.

[26] Parthasarathy R.V., Martin C.R., Nature, 369 (1994), 298.

[27] Xu J., Hou J., Zhang S., Nie G., Pu S., Shen L., XIAO Q., J. Electroanal. Chem., 587 (2005), 345.

[28] Bezoari M.D., Kovacic P., Gronowitz S., HornFELDT A.B., J. Polym. Sci. Lett. Ed., 19 (1981), 347.

[29] Aqad E., Lakshmikantham M.V., CaVA M.P., Org. Lett., 3 (2001), 4283.

[30] Patra A., Bendikov M., J. Mater. Chem., 20 (2010), 422.

[31] Narita Y., Hagiri I., TAKahashi N., TAKeda K., Jpn. J. Appl. Phys., 43 (2004), 4248.

[32] Salzner U., Lagowski J.B., Pickup P.G., Poirier R.A., Synthetic Met., 96 (1998), 177.

[33] InOUE S., NAKANishi H., TAKIMIYA K., Aso Y., OTSUBo T., Synthetic Met., 84 (1997), 341.

[34] Peulon V., Barbey G., Outurquin F., Paulmier C., Synthetic Met., 53 (1993), 115.

[35] Del Valle M.A., Ugalde L., Diaz F.R., Bodini M.E., Berne'De J.C., Chaillou A., Polym. Bull., 51 (2003), 55.

[36] Sauvajol J.L., Chenouni D., Hasoon S., LerePorTe J.P., Synthetic Met., 28 (1989), C293.

[37] Glenis S., Ginley D.S., Frank A.J., J. Appl. Phys., 62 (1987), 190.

[38] Yoshino K., Kohno Y., Shiraishi T., Kaneto K., Inoue S., Tsukagoshi K., Synthetic Met., 10 (1985), 319.

[39] Huang W.S., Park J.M., Chem. Commun., (1987), 856.

[40] Zotti G., Gumbs R., Polythiophene and Polypyrrole Copolymers, in NALWA H.S. (Ed), Handbook of Organic Conductive Molecules and Polymers, Wiley, Chichester, 1997.

[41] Alakhras F., Holze R., J. Appl. Polym. Sci., 107 (2008), 1133.

[42] Alakhras F., Holze R., Electrochim. Acta, 52 (2007), 5896. 
[43] Alakhras F., Holze R., Synthetic Met., 157 (2007) 109.

[44] Alakhras F., Holze R., J. Solid State Electr., 12 (2008), 81.

[45] Arjomandi J., Alakhras F., Al-Halasah W., Holze R., Jordan J. Chem., 4 (2009), 279.

[46] Ong T.T., NG S.C., Chan H.S.O., Polymer, 44 (2003), 5597.

[47] Ng S.C., Chan H.S.O., Ong T.T., Kumura K., MAZAKi T., KobAYASHi K., Macromolecules, 31 (1998), 1221.

[48] Kunugi Y., Takimiya K., Yamane K., Yamashita K., Aso Y., Оtsubo T., Chem. Mater, 15 (2003), 6.

[49] Yamamoto T., Zhou Z.H., Kanbara T., Shimura M., KizU K., Maruyama T., Nakamura Y., Fukuda T., LeE B.L., Ooba N., Tomaru S., Kurihara T., Kaino T., Kubota K., Sasaki S., J. Am. Chem. Soc., 118 (1996), 10389.

[50] Jenkins I.H., Salzner U., Pickup P.G., Chem. Mater., 8 (1996), 2444.

[51] Van Keuren E., Wakebe T., Andreaus R., MohWald H., Schrof W., Belov V., Matsuda H., Rangel-Rojo R., Appl. Phys. Lett., 75 (1999), 3312.

[52] Li L., Chen W., Xu N., Xaio Z. G., Xue G., J. Mat. Sci., 39 (2004), 2395.

[53] Wan X., Zhang W., Jin S., Xue G., You Q., Che B., J. Electroanal. Chem., 470 (1999), 23.
[54] Wan X., Yan F., Jin S., LiU X., Xue G., Chem. Mater., 11 (1999), 2400.

[55] Inzelt G., Pineri M., Schultze J.W., VorotyntSEV M.A., Electrochim. Acta, 45 (2000), 2403.

[56] Pu S., Houb J., Xua J., Nieb G., Zhang S., Shen L., XIAO Q., Mater. Lett., 59 (2005), 1061.

[57] Xu J., Shi G., Xu Z., Chen F., Hong X., J. Electroanal. Chem., 514 (2001), 16.

[58] Shreepathi S., Holze R., Chem. Mater., 17 (2005), 4078.

[59] Wan X.-B., Li L., He J.-B., Zhou D.-S., Xue G., WAng T.-W., J. Appl. Polym. Sci., 86 (2002), 3160.

[60] Roncali J., Chem. Rev., 92 (1992), 711.

[61] Asavapiriyonont S., Chandler G.K., GUNAWARdena G.A., Pletcher D., J. Electroanal. Chem., 177 (1984), 229.

[62] Genies E., Bidan G., Diaz A.F., J. Electroanal. Chem., 149 (1983), 113.

[63] Pinzino C., Angelone R., Benvenuti F., Carlini C., Galletti A.M.R., Sbrana G., J. Polym. Sci. Pol. Phys., 36 (1986), 1901. 